\title{
INTRODUCING GEOGRAPHY AND READING MAP SKILLS TO KINDERGARTEN CHILDREN BY USING LARGE-SCALE GIANT MAPS
}

\author{
Christina Zisi, Aikaterini Klonari, Nikolaos Soulakellis and Georgios Tataris \\ Department of the Geography, University of the Aegean, Mytilene, Greece
}

\begin{abstract}
The construction of space in children develops gradually, as they grow up and is related both to their environment and to their spatial and/or geographical experiences. According to previous studies, spatial thinking is malleable, and can be developed with the use of appropriate teaching interventions and educational material. Geospatial thinking and reading map skills required to decode map symbols are a relatively new and very interesting topic in kindergarten's education. Significance of this study is the creation of two large-scale giant maps, laminated, and appropriate to accompany teaching material that can be used in a teaching intervention based on the Greek kindergarten curriculum. The first map (scale of 1:1000) is a map of the city of Mytilene, and the second one (scale of 1:20000) is of the island of Lesvos; both have dimensions $3 X 4$ meters. The purpose of this study is to present the creation of spatial teaching material, so that map skills in Kindergarten education can be cultivated and developed in order to provide kindergarten teachers with large scale-giant maps and encourage them to introduce them to their teaching, as large scale-giant maps are really powerful educational tools for the development of their pupils' spatial skills.
\end{abstract}

\section{KEYWORDS}

Giant maps, kindergarten kids, geography education, reading map skills.

\section{INTRODUCTION}

Geography at young ages plays a crucial role in developing children's spatial thinking and building their geographical skills. Thus, Geography is quite valuable, and it should be explicitly taught in school at a very young age, because, as children develop geo-literacy skills, they could better understand and experience the world around them; it also helps them have fun [1]. Teaching kids about maps means providing them with skills and understanding required to read, interpret, and produce maps, while teaching with maps means enabling kids to learn spatial reasoning and problem solving through maps [2]. The main element of Geography is the space, the understanding of its various forms [3] and the understanding of how the individual can interpret space structurally, symbolically, and functionally [4]. According to [5: 315-316], space is divided in: (1) "figural space," the space that is understood when the person is still; (2) "vista space," which is larger than the person and is perceived with little movement (one room, one square); (3) "environmental space," the space that is much larger than the body and in order to be perceived the person should move in it (buildings, neighbourhoods, cities); and (4) in "geographical space," which cannot be perceived only by movement, but symbolic representation is required to understand it. Maps and models can turn "geographical space" into "figural space," thus making it understandable. The way we think about space, when referring to a smaller level, is called spatial thinking or spatial abilities, whereas, when referring to large geographical space, is referred to either as geospatial thinking or as geospatial abilities [6]. 
Children interact with the space around them, experience it, discover and explore it and, by interacting with it, build their perception and knowledge [7]. Space [8] is gradually structured from the first year of life and the movements of the body are essential. Children of 2-6 years of age can gradually represent mentally the surrounding area, while they do have difficulties understanding the geographical space.

This research suggests an effective teaching intervention with the use of appropriate teaching material that will lead to kindergarten pupils' development of spatial abilities and reading map skills according to the curriculum of the kindergarten.

\section{Literature REVIEW}

\subsection{Geography and spatial skills in kindergarten}

Spatial skills are neglected in schools in contrast with language and mathematics [9], despite the fact that spatial skills can be improved when appropriately planned interventions are available [10].

The environment of the kindergarten provides opportunities to children to get familiarized with the concept of space and acquire spatial skills [11]. In order to achieve better performance in spatial activities, kids need appropriate pedagogical interventions that encourage, support, plan and implement age-appropriate activities, by using games (like puzzle or brick games) and "spatial" words, thus encouraging movements and gestures, routes and by using maps or models [12]. Although all agree teaching spatial skills interventions should start from kindergarten, there have not been enough studies on the development of spatial thinking at this age.

Practicing with appropriate activities - such as mental rotation - and in a proper pedagogical environment, by incorporating and including spatial symbols, [13] argues that it helps to develop quick and more effective spatial thinking. The use of verbal, mathematical and spatial representations should be integrated into the educational process. Davis and Hyun [14] argue that, when children are asked to represent their home space, they can work together, negotiate and with a high expression of spatial representation to construct the map. Spatial scale skills are developed particularly between 3 and 5 years of age (preschool age) with great differentiation between individuals [15].

Gender spatial abilities studies in young children have controversial results. According to some researchers, boys outperform girls in activities that require spatial ability and perception [16], navigation in a straight and inclined plane [17] and in skills requiring spatial-visual talent [18]. Differences in Visuo-Spatial Working Memory (VSWM) lead to differences in orientation ability with boys achieving better. Nevertheless, when orientation activities do not require a high degree of spatial-visual memory, gender differences are eliminated, argue [19]. Early interventions can have great effect on spatial performance of both genders [20]. However, there are studies which found no gender differences in visual-spatial skills [21], in mental rotation ability [22] and in spatial ability in young children [23].

What is also important is the impact of socioeconomic status [24] and the different spatial play experiences, as boys are more likely to play with blocks and spatial toys that have been found to increase spatial abilities [25]. However, when boys and girls have both equal access to blocks, it has been shown that there have been no gender differences in blocks building skills [26]. [27] insist that spatial ability is higher among young girls and favour boys as they are getting older. Both genders use different strategies for orientation and mental rotation [28]. Individuals who are 
capable of using more strategies achieve more, while those with higher spatial abilities can better express their strategies verbally [29].

Vital for spatial thinking development is the understanding of the structure of space and the knowledge of what we can do in it. Geography and cartography with map making provide a basic tool for representing, describing, and understanding space and the relationships that govern it [30: 36]. Since 1988, it has been established that the practice of using maps in kindergarten [31] is an appropriate tool to develop spatial skills and skills needed in geographical education. Maps are much more than pointing the way; they are tools to think as they present a wide variety of other variables (economic, population, etc.) [32].

Maps are crucial for children to acquire geographic knowledge and map skills at the kindergarten [31], and can be introduced in kindergarten classroom as a tool to improve spatial thinking and eliminate gender or socioeconomic differences [32]. Reviews indicate that, although teachers are sceptical as to whether children can use a map effectively [2], children, instead, love maps both in preschool [33] and in primary school [34]. Although pupils do not actually use maps before and have minimal training, they usually know how to use them. However, pupils with less developed spatial abilities were found to create "poor" map drawings, make fewer movements, and have poorer vocabulary when exposed to large-scale maps [35]. Giant maps can represent much different spatial information associated with symbols on the map surface [36]. Large-scale maps allow children of 3-6 years of age to explore them with their entire bodies with sensory experiences, kinesthetic learning, and hands-on activities. They can recognize places, use landmarks, show points of interest on the map, understand size differences, compare distances, orient themselves and recognize symbols that represent real objects [37]. Studies have shown that children are more familiar with their narrow environment (neighbourhood), and are able to recognize important city attractions [38]. Large-scale maps are of greater interest to pupils and teachers, and can incorporate other subjects into teaching. Moreover, although boys and girls respond differently, while dealing with maps, reduction in inequalities has been observed in their spatial thinking [39: 189]. Large-scale in giant maps present spatial information in greater details and size, thus making it easier for young children to understand.

What is recommended for young children teaching intervention is to use specific activities that require body movement, and then to build on this knowledge with the use of gestures [40]. Simultaneous use of gestures and speech are more effective [41]. Children who actively explore their environment are more able to handle spatial-visual information, while those with low spatial abilities can verbally describe their environment but cannot mentally represent it [42]. [43] argue that learning space, sizes and time should be done through movement. When children interpret with maps, there was greater improvement in children who made gestures and movements with their bodies that simulated the movement of objects on maps. When children use gestures instead of body movements, it has been shown that children had to generalize, a fact that led to the improvement of their abilities even after the end of the intervention.

In the Greek kindergarten curriculum spatial thinking and learning of geographical concepts do not exist with autonomous activities; instead, they are integrated in various learning subjects [44], such as: a. in environmental studies and, more specifically, in "the child in the wider human-induced environment"; $b$. the construction of maps and spatial codes, in the direction of planning language activities; and c. in the unit of mathematics and, more specifically, in "simple time-spatial concepts," with emphasis on the dimension "space". It is clear that Geography and, more particularly, the development of spatial thinking is not a subject of high importance or first priority in Greek kindergarten education. 


\section{Methodology}

\subsection{Procedure}

The purpose of this study is to introduce Geography and reading map skills in kindergarten by creating two large-scale giant maps: one of Mytilene city and one of the island of Lesvos, with their accompanying teaching material, so an effective teaching intervention is designed.

All these procedures, which are discussed below, must follow an instructional model that supports the teaching intervention and all activities, design, and creation of maps as well as the creation and collection of teaching material. After a review of most popular instructional models had been made $[45,46]$ the Addie model was found to be the most commonly used instructional model for training needs. We considered Addie model an effective design method and flexible enough to help us create successful teaching material and intervention.

Addie model is a five-phase process (and an acronym of these five phases) which are:

1. Analysis. In this phase, the researcher should know all about the learners' needs, previous knowledge, and choices.

2. Design. This is the phase we design maps, materials, and the teaching intervention.

3. Development. It refers to the creation of all the models have been designed in the previous phase and the detailed writing of the intervention. Before development phase has been completed, the researcher has the opportunity to run a pilot session, to take some feedback on the designed course and adjust it, if necessary.

4. Implementation. This is where the designed course, after all the adjustments (if necessary) have been made, is put into action. Now, it is the use and test of the largescale giant maps, the other materials, and the teaching intervention if they are appropriate for the pupils. If researcher's work was well organized in the previous phases, this stage will be smooth and successful.

5. Evaluation. Evaluation has two parts. The first one is a formative evaluation at all stages; it is an ongoing procedure after every phase and evaluates every step. The second one is a summative evaluation, when final evaluation of maps, teaching materials and intervention is made.

According to ADDIE model:

\subsubsection{Analysis}

All theoretical review was presented at the beginning, and the next step was to determine the population and the sample that would participate in the research according to the needs and knowledge had been described.

Population and Sample

Initially, a study was conducted in 2 different classes of a kindergarten school in Mytilene. After the evaluation of the findings and after the necessary (if needed) improvements had been made, the study was carried out using the same questionnaire in different kindergartens in the city of Mytilene that had been divided into experimental and control groups, at the end of the school year in order to test the teaching intervention and the giant maps as suitable spatial teaching objects. The total number of children participating in the study were to be about 100, 4 to 6 years of age. 
In Greek kindergarten, children who on the 31st of December of the year of registration would be five (5) years old are called "nipia/toddlers" or first-age, while those who on the 31st of December of the year of registration would be four (4) years old are called "pronipia/preschoolers" or second age.

\subsubsection{Design}

Spatial thinking in education and, particularly, in Greek kindergarten is integrated in other learning subjects as there is no geography in it. There are few activities related to these topics in kindergarten, and these are usually done without children using a map. There is a lack of research focusing on using maps to cultivate spatial skills. Familiarity with the use of maps, the acquisition of spatial language skills and understanding the conventions governing reading, understanding, and using a map is a new field in planning kindergarten activities. In this study, the use of a map is the basis of teaching intervention, which took place within the context of Greek kindergarten curriculum.

Our study used a questionnaire for kids at the end of the school year in kindergarten, and we found that their spatial abilities were very poor. Preschoolers who had attended the kindergarten program for 2 years performed better than preschoolers who had attended only one, but the knowledge of both groups remained quite low. From the results it became clear that, since the teaching of spatial and geographical skills is a new field in kindergarten, there is no appropriate educational material for their teaching.

Trying to fill in this gap, we based on the National Geographic Society's giant maps to create maps and material proper for kindergarten interventions. This educational material was created or collected by the researchers.

Maps were the cornerstone of this research as they formed the basis of the proposed intervention, and were to be accompanied by appropriately designed teaching material. The activities on the map were designed to help children become familiar with reading map skills, spatial skills and being able to use a map effectively.

Familiarizing children with maps is a new field in preschool education. The importance of making children able to decode the symbols of the map is extremely crucial and useful for developing their spatial thinking. In this study the two maps were designed to be cartographically accurate, attractive, and suitable for kindergarten children.

The researchers created two maps $3 \times 4$ meters each. One was the city of Mytilene map on a scale of 1:1000, and the other was of the island of Lesvos with a scale of 1:20000. The really large scale and the giant size of the maps were crucial as they could present a large number of features to be used in the activities. Kindergarten students prefer to working with large-scale maps where they can depict places and are easy to interpret [36]. The large size allows children to walk on it, lie down, take measurements with their bodies or objects, search and find familiar places on the map.

Each map had a purpose for which it was created, for this reason the map "city of Mytilene", scale 1:1000, mainly lacked details that would not be useful for children and would create noise, such as name of public buildings, museums, banks, which are concentrated in the central part of the city, and which would not help children understand the map around their neighbourhoods. On the map of Lesvos, scale 1: 20000, the hydrographic and the main road network were highlighted. In this way the children would be able to place cars on it to play and learn how they could go to the villages or locations of the island, which they often visit with their parents, thus 
understanding how they move. The scale also helped depict the settlements as polygons and not as points, giving the children to understand their shape. The map even included the names of the five largest mountains of the island, which are indicators, when one moves on the island.

The maps were printed on vinyl, so those oversized floor maps to be one-piece, easily wrapped and transported. The data had been updated by the researchers to ensure the highest possible accuracy for each scale. It was important for the study that children could find familiar landmarks on the maps, their home and the homes of relatives and friends, well-known places such as parks, stadiums, schools on the map of the city and their villages of relatives' villages and places they had visit on the island map. On the map, North is symbolized by an arrow and the letter B (from

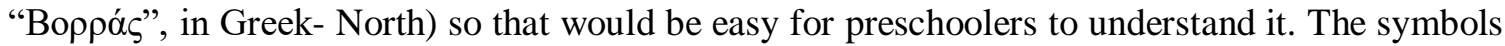
of the scale were displayed with graphics and numbers at the bottom of the map, and they would be explained in a nutshell, while the title, legend and north would be explained analytically.

Considering kindergarten children's age and trying to avoid excessive information that could confuse them, we removed many elements from the large-scale map and created a map with clarity that, at first, would have less information (than its large-scale would justify) but along the way with mobile elements (cards and objects) the map would be gradually enriched according to the development of the children's spatial ability and reading map skills. Thus, the large-scale giant maps were child-friendly, and kids could sit on them, walk, and do activities and measurements with their bodies without being provided with too much information that might be difficult for them to elaborate. The represented features could be visible and consistent with the scale and purpose of the map, and they were always grouped and classified according to these criteria. Our aim was the most accurate representation of reality and the clear, understandable symbolization of the mapped features and the symbols of the map legend [47: 78-81]. According to the Robinson and his colleagues [48: 387], the goals were of two kinds:

- Real: It was a necessity for the researchers to clarify the information (data) that would be represented on each map, considering both the pupil's young age and the cartographic accuracy of the maps.

- $\quad$ Aesthetics: Colours, hue, value, saturation, brightness and colour combinations, shapes and size had to be chosen in such a way that the final map would be balanced, aesthetically pleasing and attractive to the young pupils. The final map had to be an interesting teaching material with proper artistic data expressions, able to help preschoolers interact with it and learn from it. Visual balance and hierarchy were important, so all information on the maps was displayed with adequate emphasis and positioned properly. Our maps were not too cluttered, and, finally, nothing was too intense or too bright or too big or in the wrong place; instead, all the objects on the maps had to have the right proper shape and place [48:391) and look organized. Maps with good visualization and balance encouraged children's involvement in activities, facilitated them to interact and diminished misunderstandings from unbalanced or too much information.

Important for the making of those maps was the type and the size of letters to be used on them. Kindergarten should give children access to all the letters of the alphabet according to NCRI, 2011 [49] and encouraged them to "read" and "write" with or without pattern (copy) all letters. It is important for them to recognize enough letters, to distinguish upper from lowercase letters, and to understand the different use of capital and small letters [50]. Literature suggests that the lowercase letters be included in the teaching process after the uppercase letters [51]. Letters on the Mytilene map (Figure 1) that would be used first were chosen to be uppercase, while those on the Lesvos map (Figure 2) lowercase. 
The large size of the letters (larger than letters of size 12) made letters readable for young children attending first grade [52]. The font was chosen to be simple fine lines without any slant, extra horizontal strokes (sans -serif type) or characteristics such as stroke width, and letter height and width as it was found [53] that simple fonts are preferable for kindergarten and first grade elementary school pupils, as they provide readability and legibility.

The colour palettes used on the maps were chosen using appropriate software to come to an aesthetic result and take into account to match certain colours with certain real-world things: blue (water), green (forest). Important was the use of the right hue, intensity, and saturation. All symbols were made to be as simple as possible without extra lines or layers. Design and shape of the symbols made in order to have the proper visualization and the correct size according to the importance, the correct direction and colour harmony [54] using visual variables correctly.

\subsubsection{Development}

The data of the maps were updated, the colours were chosen and the design was completed in previous phase, test prints and corrections were made and then the final map of the city of Mytilene was printed in this phase (Map1, Figure 1).

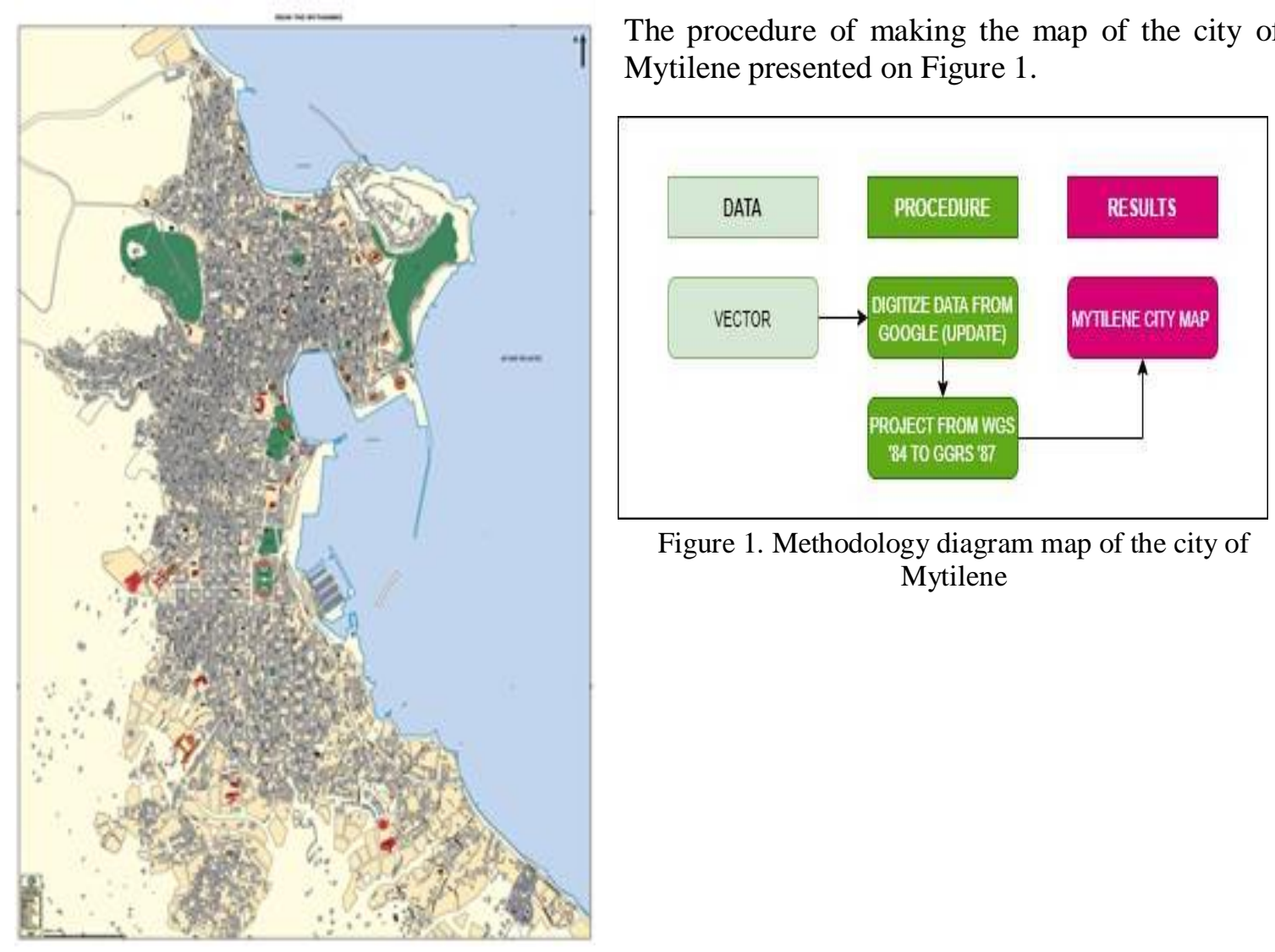

Map 1. Map of the City of Mytilene

The procedure of making the map of the island of Lesvos presented in Figure 2 
International Journal of Education (IJE) Vol.9, No.4, December 2021

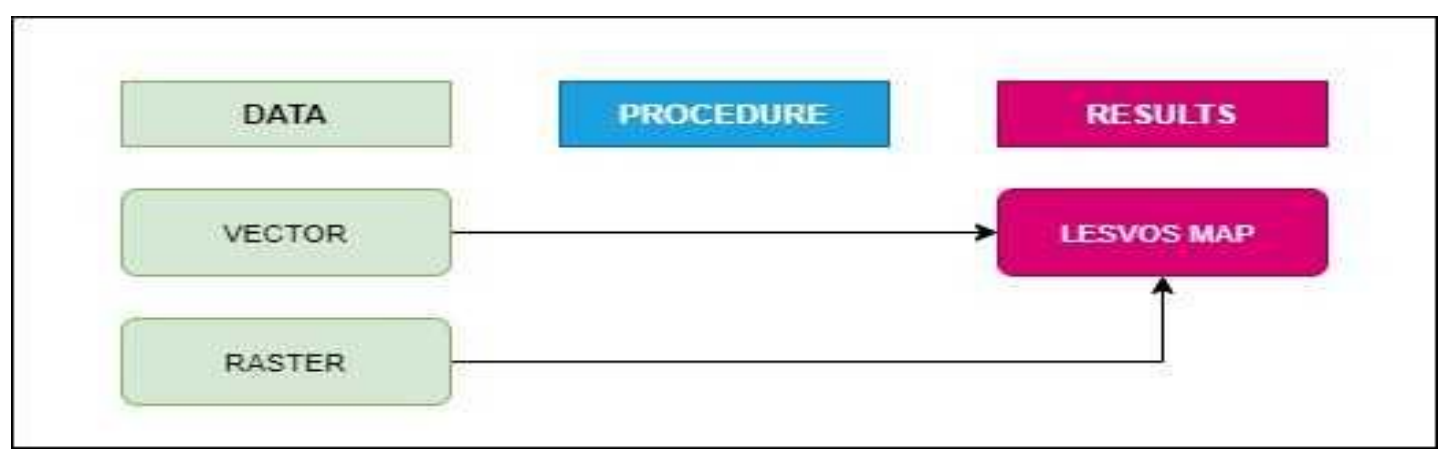

Figure 2. Methodology diagram of Lesvos' map.

Observations made on this map led to further improvements to the map of the island of Lesvos (e.g. the size of the legend), then we made test printouts and the final printing (Map 2).

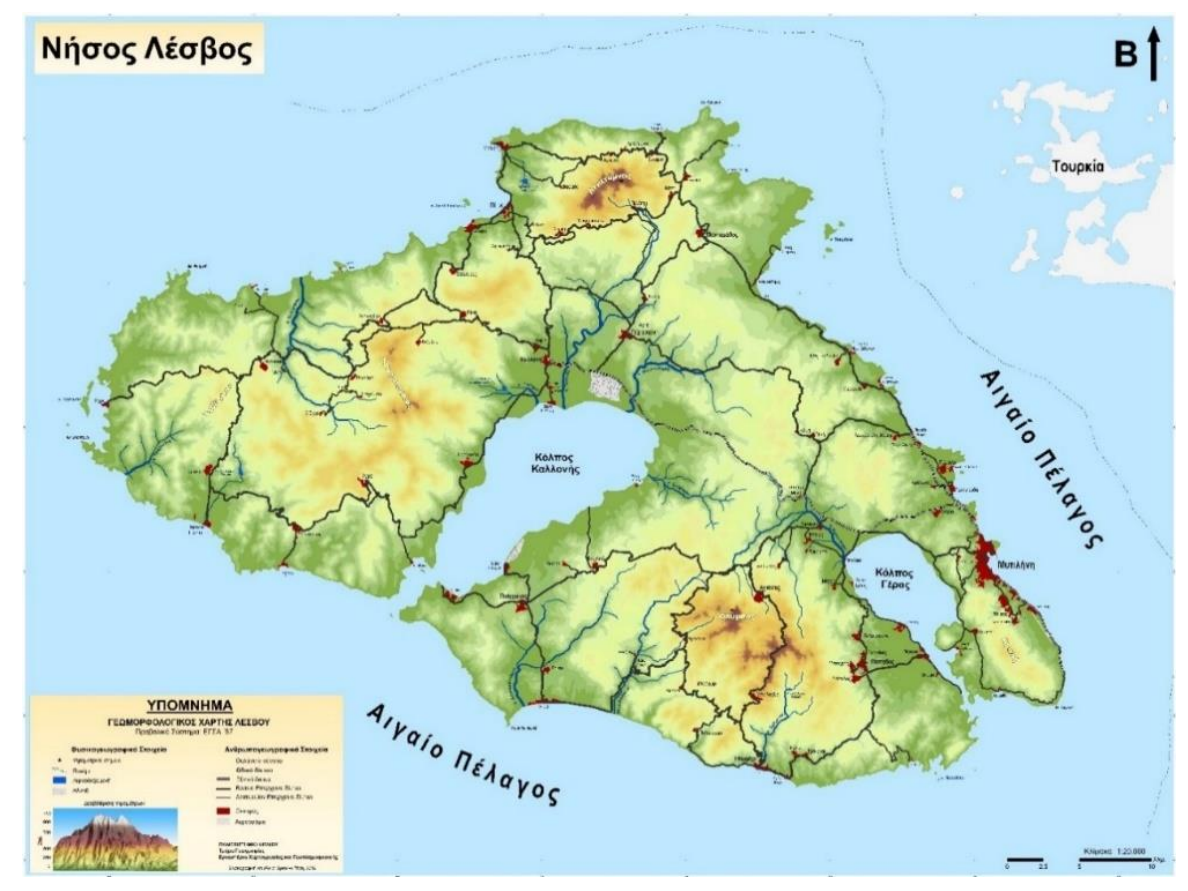

Map 2. Map of Lesvos

Teaching material that had been collected or created by the researchers to support geographical knowledge and spatial abilities activities would be used in the teaching intervention project. This material consists of compasses, miniatures from houses, buildings, cars, mopeds, people, plants, laminated cards with pictures of typical city buildings, laminated cards with island products, cards with orientation symbols, hoops, ribbons, cones, bricks, and ropes.

Data were collected by using a pre- and post-questionnaire to investigate: a) the kindergarten's children ability to read a map; b) their ability to identify and clarify map symbols, such as title and legend; c) to understand basic features, such as the symbols of roads, rivers, cities, the colour, or the reason of the different sizes of the letters; d) the scale of a map; e) their skills to navigate on the map; and f) their ability to sketch a simple map. Due to the pupils' age and their inability to read and write the completion of questionnaire was done (pre-) and was to be done (post) again with Kindergarten teachers' or the researcher's help, who would ask the questions and write the 
answers. Some questions on how to create a map, how to draw a road or how to put point symbols on the map were completed by the children themselves.

Children's knowledge was studied at the end of the school year using a questionnaire and showed their small spatial knowledge and skills. The teaching intervention material was created, and then, this teaching intervention would be applied in the classroom. All preschoolers participating in the survey would complete the same questionnaire at the beginning and at the end of the school year. The children of the experimental group would attend the teaching intervention using largescale giant maps that we had made, while the control group not.

Answers to each question of the questionnaire were categorized and points were given, the correct answer had 1 or 2 grades, the wrong answer 0 , and the maximum was 60 grades. Thus, each preschooler had a score in each question and a total score. Then, a quantitative analysis of the children's scores would be done to get the final findings of the study.

\subsection{The teaching procedure}

Our teaching intervention implied hands-on activities as a way for preschoolers both to learn about and with maps. Furthermore, the children were encouraged to be active, speak, reflect upon and create in an active and participative way [55]. The teaching intervention was designed to be implemented in three stages:

1. Introductory activities with a simple map, the use of the compass and the four cardinal directions. This stage lasted 2 to 3 teaching hours, 1 day or 2 days.

2. Activities using the large-scale giant maps dimensions $3 \times 4$ meters in which children could recognize well known places, their neighbourhood, their school, their villages [14].

\subsubsection{Activities using the large-scale giant map of Mytilene city}

Indicative activities: Children learned that a map is a representation of the world that describe and convey information graphically. In this map children learned the symbols of the map: title, legend, orientation (B and/or arrow) and "read" the map. They placed the map in the correct orientation, turning it up to point B pointing North (Boppós, in Greek). Children decoded the legend with the help of kindergarten teachers and looked for well-known public buildings, such as: the police station, the hospital, schools, churches, kindergartens, or buildings where their parents worked, and they tried to find their homes or houses known to them on the map. They learned to use the map in problem-solving activities "I'm at school and I want to go to the hospital, but I want to pick up my brother from the nearby nursery, how am I going?" "which way should I take to go to my dad's work at the police station?" They measured distances and found that the distance from one point to another and the path they follow is not in a straight line. They surrounded the neighbourhoods with wreaths and described what was inside the wreath and what they could find there. They "drove" a car on the road to their home and saw the need for landmarks. They found out which children lived nearby, and verbally described the distance or route they had to follow to meet them. They read the names of the streets on paper and tried to find them in a specific place on the map. The letters on this map were uppercase.

\subsubsection{Activities with the large-scale giant map of the island of Lesvos}

Indicative activities: Children observed the two maps both spread out on the floor, and could observe the difference in their scale. A large map (first one) was just the red mark on the other map (second one). The difference between Lesvos and Mytilene (capital of the island) that often confuses children was clear, and children could see the difference with their own eyes. The 
activities to learn to use the North for orientation, to read the title and the legend were often repeated. The kindergarten teacher helped the children observe the relief of the island and learn what a mountain, a plain, a river, a bay, a gulf, a port and altitude is, and how they were represented in colour on the map by reading the legend to them. Typical points - such as salt pans, airport, port, and their usual symbolism - were shown on the map with mobile laminated cards. It became clear to the children that a map is always the creation of a cartographer and, despite the usual conventions governing a map, it is always necessary to read the legend. Children could make movements on the map, make gestures to guide their team member to complete a mission on the map, use cars to travel to villages and certain places; they were also asked to make assumptions about distances and route length and confirm them experimentally. They used the map following instructions (e.g. one step to the left, then 2 steps to the right), they solved problems (if I want to buy salt, where will I go? If I am in Agiasos - a mountainous village of Lesvos - which is the nearest beach to go swimming?). They used cards with symbols [56] to show what is in each place, for example, beach and airport.

The teaching material and the entire teaching intervention had been tested in pre-test activities.

\subsection{The pilot session sample}

In this paper presenting the findings of the pilot session as the last two phases of the Addie model (implementation and evaluation) will be completed later. The total number of pupils participating to the pilot session was $42 ; 21$ pupils were in the experimental group, and 21 pupils were in the control group. Both groups attended the two classes of the same kindergarten in Mytilene. The distribution in the kindergarten classes was done in absolute alphabetical order, after the children had first been divided into groups according to age, gender and willing to attend the all-day program. Finally, the number of girls and boys, toddlers and preschoolers were the same.

The pilot session was very interesting and engaging for the children, and some of their photos are presenting in Figure 3.

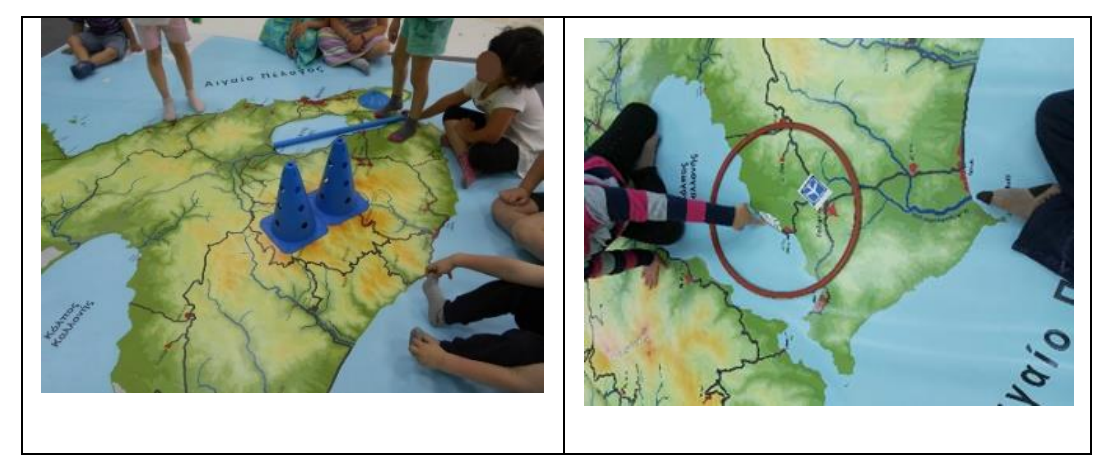

Figure 3. Photos of children in hands-on activities on Lesvos' map.

The boys were 16 and the girls 26. The children who on December 31 of the year of registration reached the age of five years were 26 (15 girls and 11 boys), and those who reached the age of four were 16 (11girls and 5 boys), the youngest child at the beginning of the pilot session was 4 years old, and the eldest 6,5 years old with an average age of 5,2 years old. 


\section{RESUltS AND FindingS}

We found that, while both groups had students with similar abilities at the beginning, at the end, the improvement of the experimental group was spectacular (Table 1). The maximum score of the control group became 36.5 from 37 and the mean from 17.76 became 20.57. This indicates that there was improvement during the year, but some skills were not taught at all to the control group. The improvement of the experimental group was impressive, the minimum score from 8.5 became 52, the maximum from 32 was 60 and the mean from 18.07 became 57.36.

Table 1. Total grades

\begin{tabular}{|l|l|l|l|l|l|l|}
\hline & \multicolumn{4}{|l|}{$\begin{array}{l}\text { Total grades at the beginning of the } \\
\text { school year }\end{array}$} & \multicolumn{3}{l}{ Total grades at the end of the } \\
school year
\end{tabular}

Analysis of children who on December 31 of the year of registration reach the age of five (5) years showed the significant improvement of the experimental group, the maximum score from 32 increased to 60 the mean from 20.54 increased to 58.33, while in the control group the mean increased from 21.28 to 24.67 , whereas the maximum score had a slight decrease from 37 to 36.5 (Table 2).

Table 2. Grades of children who on December 31 of the year of registration reach the age of five (5) years

\begin{tabular}{|c|c|c|c|c|c|c|c|}
\hline & & \multicolumn{3}{|c|}{$\begin{array}{l}\text { Total grades at the beginning of } \\
\text { the school year }\end{array}$} & \multicolumn{3}{|c|}{$\begin{array}{l}\text { Total grades at the end of the } \\
\text { school year }\end{array}$} \\
\hline & $\mathrm{N}$ & Min & Max & Mean & Min & Max & Mean \\
\hline Control group & 14 & 10 & 37 & 21.28 & 13 & 36.5 & 24.67 \\
\hline Experimental group & 12 & 11.5 & 32 & 20.54 & 53 & 60 & 58.33 \\
\hline
\end{tabular}

Children's improvement in experimental group who on December 31 of the year of registration reach the age of four (4) years was extremely impressive. Initially, the minimum score was 8.5 and became 52, while the maximum from 20.5 to 60 and mean from 14.77 rose to 57.36 (Table 3). Initially, control group had a minimum of 7 and became 8.5, whereas the maximum was 16 and became 15 and mean from 10.71 became 12.35 .

Table 3. Grades of children who on December 31 of the year of registration reach the age of four (4) years

\begin{tabular}{|c|c|c|c|c|c|c|c|}
\hline & & \multicolumn{3}{|c|}{$\begin{array}{l}\text { Total grades at the beginning of } \\
\text { the school year }\end{array}$} & \multicolumn{3}{|c|}{$\begin{array}{l}\text { Total grades at the end of the school } \\
\text { year }\end{array}$} \\
\hline & $\mathrm{N}$ & Min & Max & Mean & Min & Max & Mean \\
\hline Control group & 7 & 7 & 16 & 10.71 & 8.5 & 15 & 12.35 \\
\hline Experimental group & 9 & 8.5 & 20.5 & 14.77 & 52 & 60 & 5736 \\
\hline
\end{tabular}

A comparison between boys and girls' grades (Tables 4 and 5) at the beginning of the school year shows that boys performed little better than girls in both groups on maximum and mean scores and in minimum of control group. The boys of the control group had minimum 7 maximum 37 and mean 18.93, whereas girls had 7.5 35.5 and 17.18, respectively. Girls of both groups had almost similar means and boys of the experimental group had a slight better mean 19.16 to 18.93. At the end of the school year, the boys in the control group showed a slight improvement with the minimum grade to become 8.5 and the mean 19.28 but the maximum performance from 37 
decreased to 31.50 and girls' minimum became 10.5 maximum 36.5 and mean 21.21. Experimental group showed significant improvement without any differences between the two groups. Boys had a minimum of 52.5, and the girls 52, both boys and girls had maximum 60 , boys' mean were 57.33 and the girls' 57.37 . Skills that the boys had in the beginning of the year were declined, while those of the girls were improved.

Table 4. Boys' grades

\begin{tabular}{|l|l|l|l|l|l|l|l|}
\hline & & \multicolumn{3}{|l|}{$\begin{array}{l}\text { Total grades at the beginning of } \\
\text { the school year }\end{array}$} & $\begin{array}{l}\text { Total grades at the end of the } \\
\text { school year }\end{array}$ \\
\hline & $\mathrm{N}$ & Min & Max & Mean & Min & Max & Mean \\
\hline Control group & 7 & 7 & 37 & 18.93 & 8.5 & 31.50 & 19.28 \\
\hline Experimental group & 9 & 10 & 32 & 19.16 & $\mathbf{5 2 . 5}$ & $\mathbf{6 0}$ & $\mathbf{5 7 . 3 3}$ \\
\hline
\end{tabular}

Table 5. Girls' grades

\begin{tabular}{|l|l|l|l|l|l|l|l|}
\hline & & \multicolumn{3}{|c|}{$\begin{array}{l}\text { Total grades at the beginning of } \\
\text { the school year }\end{array}$} & \multicolumn{3}{l|}{$\begin{array}{l}\text { Total grades at the end of the } \\
\text { school year }\end{array}$} \\
\hline & $\mathrm{N}$ & Min & Max & Mean & Min & Max & Mean \\
\hline Control group & 14 & 7.5 & 35.5 & 17.18 & 10.5 & 36.5 & 21.21 \\
\hline Experimental group & 12 & 8.5 & 25 & 17.25 & $\mathbf{5 2}$ & $\mathbf{6 0}$ & $\mathbf{5 7 . 3 7}$ \\
\hline
\end{tabular}

It was found that Geography and reading map skills, when taught in the traditional way, children only slightly improve their skills and knowledge during the school year. The maximum performance in the control group was 37 by a boy at the beginning of the year who on December 31 of the year of registration reaches the age of five (5) years. Children who on December 31 of the year of registration reached the age of four (4) years had a slight decrease (16 to 15) at the end of the study.

After the proposed teaching intervention with the use of large-scale giant maps and the teaching material that accompanied them, all children had impressive improvement. Scores of experimental group after teaching intervention with the use of large maps and the supporting teaching material were impressive. All children had a great improvement with the older children having better performance. Even older preschoolers had a better final score, smaller children who on December 31 of the year of registration reached the age of four (4) years had higher improvement. It was found, firstly, that the performance in spatial skills depends on age, and, secondly, that the effective teaching using appropriate material in kindergarten develop pupils' specific spatial skills.

Findings agree with previous researches, and indicate that Geography and reading map skills can be taught in young children with proper teaching interventions and teaching materials [57]. These findings indicate that teaching intervention using large-scale giant maps and the accompanied teaching materials leads to impressive children's scores in teaching and developing Geography and reading map skills and is absolutely proper to use in kindergarten pupils.

The two final phases will take place later, and we now have just presented the first three phases of the pilot session and their evaluations, such as the large-scale giant maps, the teaching material and the teaching intervention. Teaching Geography and reading map skills and developing spatial thinking is a very new topic in kindergarten curriculum. Spatial thinking is relatively new field in education and is almost non-existent in kindergarten's education, without clearly targeted and well-organized activities described in the kindergarten curriculum; there is no proposal for appropriate spatial teaching material either. This study aims to fill in this gap and be a complete, sufficient, and effective proposal for teaching in kindergarten. 


\section{CONCLUSION AND DISCUSSION}

This is a part of the study that aims to fill in a big gap in spatial education by trying to adapt the National Geographic Society's giant maps concept and make it suitable for the Greek kindergarten's children; it has also presented a teaching intervention, maps, and teaching material.

First findings indicate kids' strong interest in and love of large-scale giant maps and the impressive scores in geographic knowledge and reading map skills of experimental group. It is a very hopeful proposal to fill in the gap in teaching Geography and reading map skills in kindergarten.

We have observed a decrease in control group's maximum scores (excluding girls) at the end of the school year. The first questionnaires (at the beginning of the school year) were completed shortly after October (kindergartens start on September 11), and during this time the children are taught basic knowledge of the island of Lesvos where they live. The knowledge acquired at the beginning of the school year in control group was not maintained by some of them until the end of the school year.

Pilot sessions have shown the great improvement of the children who attended the teaching intervention using the large-scale giant maps and the big difference in the degree of achievement between the experimental group and the control group in the end of the school year. The children in the control group who attended kindergarten for 2 years had a significantly lower performance than the children of the experimental group who attended only 1 year in kindergarten in the end of the school year, although in the beginning of the school the mean of the children attending their first year in kindergarten was almost half of the mean of the children of the next grade.

We have found no gender differences, so our findings agree with previous research [23]. Pupils have shown great interest in the specific project with using large-scale giant maps, as previous studies refer to [39], and loving maps, the joy and fun that these spatial activities on the largescale giant maps have given them.

This study could encourage kindergarten teachers to introduce spatial thinking, Geography and reading map skills as teaching topics and provide them with basic ideas and proposals of how to incorporate them in their teaching. Considering that early intervention is crucial for individual development, the malleability of spatial thinking and the fact that spatial skills can be improved when interventions properly designed as suggested by researchers [58, 11], introducing geography from kindergarten [1] can have a significant impact on children's geographical and spatial thinking and improve their spatial outcomes. The intervention we are proposing could be an answer. Focusing on the age group of 4-6 years and considering the great importance of early intervention in improving children' skills [10], the proposed intervention is particularly important even if it has not been extensively tested. The lack of proper spatial training of kindergarten teachers could be addressed with this intervention with hands-on activities and kindergarten teachers could be encouraged to use it.

The pilot session has shown the great effectiveness of the proposed teaching intervention with the use of large-scale giant maps in the kindergarten. With no gender differences and with lot of fun, kindergarten pupils of the experimental group achieved great performance in reading map skills and geographic knowledge. 
When the implementation and the evaluation of the two final phases are completed, we can have strong data on the success of the teaching intervention and the adequacy of using large-scale giant maps and their accompanying teaching material.

\section{RECOMMENDATIONS}

This is only a part of the three first phases of the study and presents the creation of the two large scale giant maps, the creation or selection of the accompanied to maps teaching material, the designed teaching intervention, and the pilot session of the designed teaching intervention. This research sample is not a representative one, it is just a pilot session sample, and the research was done only in one kindergarten in the city of Mytilene.

This research is self-funded.

The authors confirm there is no conflict of interest involved with any parties in this research study.

\section{REFERENCES}

[1] Hinde, E.R. (2012). Geography for Our Youngest Learners. The Geography Teacher, 9(2), 49-52. Doi:10.1080/19338341.2012.679892

[2] Bednarz, S. W. Acheson, G. \& Bednarz, R. S. (2006). Maps and map learning in social studies. Social education, 70(7), 398-432. Retrieved 23/3/2021 from https://www.socialstudies.org/system/files/publications/articles/se_700706398.pdf

[3] Thrift, N. (2009). Space: The fundamental stuff of Geography. In N. Clifford, S. Holloway, St. P. Rice, \& G. Valentine (ed.), Key Concepts in Geography. 85-96. London: Sage Publications

[4] Bailly, A.S. (1993). Spatial imaginary and geography: A plea for the geography of representations. GeoJournal, 31, 247-250. Doi: 10.1007/BF00817378.

[5] Montello, D.R. (1993). Scale and multiple psychologies of space. In: Frank A.U., Campari I. (eds) Spatial Information Theory A Theoretical Basis for GIS. COSIT 1993. Lecture Notes in Computer Science, vol 716. Springer, Berlin, Heidelberg. https://doi.org/10.1007/3-540-57207-4_21

[6] Wakabayashi, Y. \& Ishikawa, T. (2011). Spatial thinking in geographic information science: a review of past studies and prospects for the future. Procedia Social and Behavioral Sciences, 21, 304-313. Doi:10.1016/j.sbspro.2011.07.031

[7] Türel, A \& G, E. A. (2019). Effects of primary school's physical environment on children's spatial perception and behavior. International Journal of Architectural Research, 13 (2), 425-443 Doi: 10.1108/ARCH-12-2018-0048

[8] Kavouras, M., Darra, A., Kokla, M., Kontaxakis, S., Panopoulos, G., Tomaki, E. (2016). Geographic Information Science. Integrated approach and specific issues. Athens: Greek academic e-books and AIDS. Retrieved from File:///C:/Users/admin/Downloads/00_master_document.pdf

[9] Webb, R.M., Lubinski, D., \& Benbow, C. P. (2007). Spatial ability: a neglected dimension in talent searches for intellectually precocious youth. Journal of educational psychology, 99(2), 397-420. ISSN: 1939-2176. DOI: 10.1037/0022-0663.99.2.397

[10] Yang, W. Liu, H. Chen, N. Xu, P. Lin, X. (2020). Is Early Spatial Skills Training Effective? A MetaAnalysis. Frontiers in Psychology, Vol. 11 No. 1938. Doi: 10.3389/fpsyg.2020.01938

[11] Özdemir, A. \& Güven, Y. (2014). The effect of the spatial skills education program on the spatial skills of preschool children. International Journal on New Trends in Education and Their Implications, Vol.5, No. 4, 121-137.

[12] Newcombe, N.S. (2010). Picture this: Increasing math and science learning by improving spatial thinking. American Educator, Summer, 29-43. Retrieved 4-9-2017 from https://www.aft.org/sites/default/files/periodicals/Newcombe.pdf

[13] Newcombe, N.S. (2013). Seeing Relationships. Using spatial thinking to teach science, mathematics, and social studies. American Educator, Spring, 26-40. Retrieved 4-9-2017 from https://www.aft.org/sites/default/files/periodicals/Newcombe_0.pdf 
International Journal of Education (IJE) Vol.9, No.4, December 2021

[14] Davis, A.G., \& Hyun, E. (2005). A study of kindergarten children's spatial representation in a mapping project. Mathematics Education Research Journal, 17(1), 73-100. Doi :10.1007/BF03217410

[15] Frick, A., \& Newcombe, N.S. (2012). Getting the big picture: Development of spatial scaling abilities. Cognitive Development, 27, 270-282. DOI: 10.1016/j.cogdev.2012.05.004

[16] Rafi, A., Samsudin, K. A., \& Said, C. S. (2008). Training in spatial visualization: The effects of training method and gender. Educational Technology \& Society, 11(3), 127-140. ISSN 1436-4522 (online)

[17] Holmes, C.A., Nardi, D., Newcombe, N.S., \& Weisberg, S.M. (2015). Children's use of slope to guide navigation: sex differences relate to spontaneous slope perception. Spatial Cognition \& Computation, 15, 170-185. Doi: 10.1080/13875868.2015.1015131

[18] Yarmohammadian, A. (2014). The relationship between spatial awareness and mathematic disorders in elementary school students with learning mathematic disorder. Psychology and Behavioral Sciences, 3(1), 33-40. Doi: 10.11648/j.pbs.20140301.16

[19] Coluccia, E., \& Louse, G. (2004). Gender differences in spatial orientation: A review. Journal of Environmental Psychology, 24(3), 329-340. Doi:10.1016/j.jenvp.2004.08.006।

[20] Young, C.J., Levine, S. C., Mix, K. S., (2018). The connection between spatial and mathematical ability across development. Frontiers in psychology. 9:755. Doi: 10.3389/fpsyg.2018.00755

[21] Kotsopoulos, D., Makosz, S., Zambrzycka, J., \& Dickson B.A. (2019). Individual differences in young children's visual-spatial abilities. Early Child Development and Care, 2019, Ahead-of-print, 114. DOI: $10.1080 / 03004430.2019 .1699918$

[22] Bruce, C. D., \& Hawes, Z. (2014). The role of 2D and 3D mental rotation in mathematics for young children: What is it? Why does it matter? And what can we do about it? ZDM - The International Journal on Mathematics Education, 473(4), 1-14. doi:10.1007/s11858-014-0637

[23] Verdine, B. N., Golinkoff, R. M., Hirsh-Pasek, K., \& Newcombe, N. S. (2017). Links between spatial and mathematical skills across the preschool years: I. Spatial skills, their development, and their links to mathematics. Monographs of the Society for Research in Child Development, 82(1), 1-150.

[24] Verdine, B. N., Golinkoff, R. M., Hirsh-Pasek, K., Newcombe, N. S., Filipowicz, A. T., \& Chang, A. (2014). Deconstructing building blocks: Preschoolers' spatial assembly performance relates to early mathematical skills. Child Development, 85(3), 1062-1076. doi:10.1111/cdev.12165

[25] Jirout, J.J., \& Newcombe, N.S. (2015). Building blocks for developing spatial skills: evidence from a large, representative U.S. sample. Psychological Science, 26(3),. 302-310. Doi: 10.1177/0956797614563338 Retrieved 20-03-2021 from https://www.jstor.org/stable/24543656

[26] Zhang, X., Chen, C., Yang, T., and Xu, X. (2020). Spatial skills associated with block-building complexity in preschoolers. Frontiers in Psychology, 11, 563493. doi: 10.3389/fpsyg.2020.563493

[27] Samsudin, K., Rafi, A., \& Hanif, A.S. (2011). Training in mental rotation and spatial visualization and its impact on orthographic drawing performance. Educational technology \& society, 14(1), 179186. ISSN 1436-4522 (online)

[28] Wang, L. (2017). Various spatial skills, gender differences, and transferability of spatial skills. In M.S. Khine (ed), Visual-spatial ability in STEM education. 85-108. Switzerland: Springer. ISBN 9783-319-44384-3, ISBN 978-3-319-44385-0 (eBook), Doi:10.1007/978-3-319-44385-0

[29] Strasser, I., Koller, I., Strauß, S., Csisinko, M., Kaufmann, H., \& Glück, J. (2010). Use of strategy in a 3-dimensional spatial ability test. Journal of Individual Differences, 31(2), $74-77$. Doi:10.1027/1614-0001/a000013

[30] National Research Council (2006). Learning to Think Spatially. Washington, DC: The National Academies Press. Doi: 10.17226/11019

[31] Downs, R.M., Liben, L.S., \& Daggs, D.G. (1988). On education and geographers: the role of cognitive developmental theory in geographic education. Annals of the Association of American Geographers, 78(4), 680-700. https://doi.org/10.1111/j.1467-8306.1988.tb00238.x

[32] Newcombe, N.S., \& Frick, A. (2010). Early education for spatial intelligence: why, what, and how. Mind, brain, and education, 4(3), 102-111. Doi: 10.1111/j.1751-228X.2010.01089.x

[33] Anderson, J.M. (1996 November 8-10). "I love maps...but is that a road map or a weather map?". The knowledge of maps and attitudes towards mapping in Quebec schools (kindergarten, grades 111). Paper presented at the Seminar on Cognitive map, Children and education in Cartography. Gifu-Japan. Retrieved from http://lazarus.elte.hu/ccc/10years/ea/jackie2.pdf 
[34] Wiegand, P. (2006). Learning and teaching with maps. Abingdon: Routledge

[35] Kotsopoulos, D., Cordy, M., \& Langemeyer, M. (2015). Children's understanding of largescale mapping tasks: an analysis of talk, drawings, and gesture. ZDM Mathematics Education, 47, 451463. Doi 10.1007/s11858-014-0661-4

[36] National Geographic (2016). State giant traveling maps, lesson handbook. Washington, D.C: National Geographic Society. Retrieved 4-9-2017 from http://www.umt.edu/mga/documents/maplesson-handbook.pdf

[37] Mohan, A., \& Mohan, L. (2013). Spatial Thinking About Maps: Development of Concepts and Skills Across the Early Years (White Paper). Washington, D.C.: National Geographic Society. Retrieved 20-3-2021 from https://media.nationalgeographic.org/assets/file/SpatialThinkingK-5ExSummary.pdf

[38] Özgece, N., Edgü, E., \& Taluğ, M. (2015). Exploring children's perceptions and experiences of outdoor spaces. In Proceedings of the 8th International Space Syntax Symposium, Santiago, Chile, 125:1-125:14. $\quad$ Retrieved 20-03-2021 from https://www.researchgate.net/publication/289671151_Exploring_children\%27s_perceptions_and_exp eriences_of_outdoor_spaces

[39] Anthamatten, P., Bryant, L.M.P., Ferrucci, B. J., Jennings, S., \& Theobald, R. (2018). Giant maps as pedagogical tools for teaching geography and mathematics. Journal of Geography, 117(5), 183-192. Doi: 10.1080/00221341.2017.1413413

[40] Levine, S.C. Goldin-Meadow, S., Carlson, M.T., \& Hemami-Lopez, N. (2018). Mental transformation skill in young children: the role of concrete and abstract motor training. Cognitive science, 42, 1207-1228. Doi: 10.1111/cogs.12603

[41] Congdon, E. L., Novack, M.A., Brooks, N., Hemami-Lopez, N., O’Keefe, L., \& Goldin-Meadow, S. (2017). Better together: Simultaneous presentation of speech and gesture in math instruction supports generalization and retention. Learning and instruction, 50, 65-74. Doi:10.1016/j.learninstruc.2017.03.005.

[42] Fastame, M.C. (2017). Empowering visuo-spatial abilities among Italian primary school children: from theory to practice. In M.S. Khine (ed) Visual-spatial ability in STEM education. Switzerland: Springer. 125-143. ISBN 978-3-319-44384-3, ISBN 978-3-319-44385-0 (eBook), DOI 10.1007/9783-319-44385-0

[43] Bueti, D., \& Walsh, V. (2009). The parietal cortex and the representation of time, space, number and other magnitudes. Philosophical Transactions of the Royal Society B: Biological Sciences, 364(1525), 1831-1840. Doi: 10.1098/rstb.2009.0028.

[44] DIATHEMATIKON PROGRAMMA (2003). A Cross Thematic Curriculum Framework for Compulsory Education. Translated from the Official Gazette issue B, nr 303/13-03-03 and issue $B, n r$ 304/13-03-03 by members of the P.I. main staff and teachers seconded to the P.I Athens: P.I. Retrieved 20-3-2021 from http://www.pi-schools.gr/programs/depps/index_eng.php

[45] Chukwuemeka, E.J., Eyitayo, B.A., Hammed, A.A., Samaila, D. (2020). A Review of Instructional Models for Effective Teacher Education and Technology Integration. Sumerianz Journal of Education, Linguistics and Literature, 3(6), ISSN(e): 2617-1201, ISSN(p) 86-95.

[46] Aldoobie, N. (2015). ADDIE Model. American international journal of contemporary research, 5(6), 70-72. $\quad$ Retrieved 31/3/2021 from http://www.aijcrnet.com/journals/Vol_5_No_6_December_2015/10.pdf

[47] Katsios, I. \& Tsatsaris, A. (2014) Thematic cartography lectures. Thessaloniki: Disigma (in Greek).

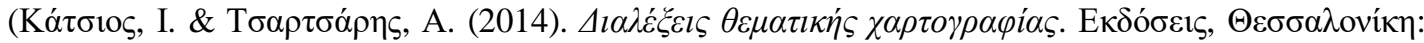

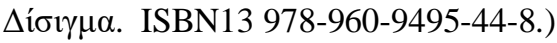

[48] Robinson, A. H., Morrison, J.L., Muehrcke, P. C., Kimerling, A. J., \& Guptill, S. C. (2002). Elements

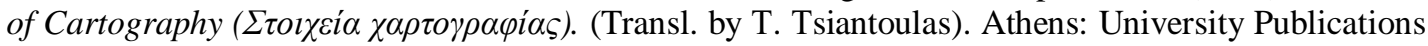
(NTUA) (1st original ed. 1995). ISBN-13 978-960-254-612-3 (in greek).

[49] Piasta, S.B., Petscher, Y., Justice, L.M. (2012). How many letters should preschoolers in public programs know? The diagnostic efficiency of various preschool letter-naming benchmarks for predicting first-grade literacy achievement. Journal of Educational Psychology, 104(4), Nov 2012, 945-958. Doi:10.1037/a0027757

[50] Reinke, W.M., Herman, K.C., Puranik, C.S., Patchan, M.M., Sears, M.M., \& McMaster, K.L. (2017). Examining Alphabet Writing Fluency in Kindergarten: Exploring the Issue of Time on Task. Assessment for Effective Intervention, 42(2), 81-96. doi:10.1177/1534508416665324 
International Journal of Education (IJE) Vol.9, No.4, December 2021

[51] Clark, G. J. (2010). The relationship between handwriting, reading, fine motor and visual-motor skills in kindergarteners. Graduate Theses and Dissertations, 11399. Retrieved 10/4/2018 from: http://lib.dr.iastate.edu/etd/11399

[52] Wilkins, A. J. (2009). Typography for children may be inappropriately designed. Journal of research in reading, 32(4), 402-412. ISSN 0141-0423 Doi: 10.1111/j.1467-9817.2009.01402.x

[53] Woods, J. R. Davis, K. \& Schaff, F. V. (2005). Effects of Typeface and Font Size on Legibility for Children. American journal of psychological research, 1(1), 86-102. Retrieved 12/04/2021 from https://www.semanticscholar.org/paper/Effects-of-Typeface-and-Font-Size-on-Legibility-for-WoodsDavis/9546938d3ba995bd1ca1866b581ad3e408c85478

[54] Brewer, C.A. (2005). Designing Better Maps: A Guide for GIS Users. ESRI PRESS. ISBN: 9781589484405

[55] Juliasz, P. C. S. (2018). Spatial thinking in preschool education: the construction of geographic knowledge. Boletim Paulista de Geografia, 99, 231-250. ISSN: 2447-0945

[56] Palmer, J.A., \& Birch, J.C. (2004). Geography in early education. London: Routledge Falmer 2nd ed. ISBN 0-203-24073-1 Retrieved $10 / 03 / 2021$ from http://ndl.ethernet.edu.et/bitstream/123456789/18585/1/79.pdf

[57] Robertson, M. Maude, A. Kriewaldt, J. (2019). Aligning mapping skills with digitally connected childhoods to advance the development of spatial cognition and ways of thinking in primary school geography. Geographical education, 32, 15-25.

[58] Klonari, A. (2012). Primary School Pupils' Ability to Use Aerial Photographs and Maps in the Subject of Geography. European Journal of Geography, 3(2), 42-52.

\section{AUTHORS}

Christina ZISI is Phd Candidate at the Department of Geography, University of the Aegean. Her current research interests are in Geography Education, reading map skills in kindergarten pupils and spatial thinking.

Aikaterini KLONARI is Emeritus Professor in Geography Department at University of the Aegean. Her research intrest is on Geographic Education and use of ICT in teaching Geography. She teaches a wide variety of courses in undergraduate and postgraduate students. She continuous to conduct research locally and internationally on Teaching and Learning Geography, Geography Curricula and on GIS in Education, Creation of Digital Learning Material.

Nikolaos SOULAKELLIS is Professor in Geography Department at University of the Aegean. His research intrest is on Cartography and Geoinformation. He teaches a wide variety of courses in undergraduate and postgraduate students. He continuous to conduct research locally and internationally on thematic mapping, 3D mapping and on geoinformation.

Georgios TATARIS is $\mathrm{PhD}$ Candidate at the Department of Geography, University of the Aegean. Member of Cartography and Geo-Informatics Lab, Department of Geography, University of the Aegean (2003-present). His research intrest is on 2D Thematic Cartography; Geoinformatics; 3D-4D Cartography; Topography; Geographical Analysis; 3D mapping. 
International Journal of Education (IJE) Vol.9, No.4, December 2021 